\title{
REVIEW
}

\section{Epidemiology of neurodegeneration in American-style professional football players}

\author{
Everett J Lehman*
}

\begin{abstract}
The purpose of this article is to review the history of head injuries in relation to American-style football play, summarize recent research that has linked football head injuries to neurodegeneration, and provide a discussion of the next steps for refining the examination of neurodegeneration in football players. For most of the history of football, the focus of media reports and scientific studies on football-related head injuries was on the acute or shortterm effects of serious, traumatic head injuries. Beginning about 10 years ago, a growing concern developed among neurologists and researchers about the long-term effects that playing professional football has on the neurologic health of the players. Autopsy-based studies identified a pathologically distinct neurodegenerative disorder, chronic traumatic encephalopathy, among athletes who were known to have experienced concussive and subconcussive blows to the head during their playing careers. Football players have been well represented in these autopsy findings. A mortality study of a large cohort of retired professional football players found a significantly increased risk of death from neurodegeneration. Further analysis found that non-line players were at higher risk than line players, possibly because of an increased risk of concussion. Although the results of the studies reviewed do not establish a causeeffect relationship between football-related head injury and neurodegenerative disorders, a growing body of research supports the hypothesis that professional football players are at an increased risk of neurodegeneration. Significant progress has been made in the last few years on detecting and defining the pathology of neurodegenerative diseases. However, less progress has been made on other factors related to the progression of those diseases in football players. This review identifies three areas for further research: (a) quantification of exposure - a consensus is needed on the use of clinically practical measurements of blows to the head among football players; (b) genetic susceptibility factors - a more rigorous set of unbiased epidemiological and clinical studies is needed before any causal relationships can be drawn between suspected genetic factors, head injury, and neurodegeneration; and (c) earlier detection and prevention of neurodegenerative diseases.
\end{abstract}

\section{Introduction}

For the last 10 years, there has been growing concern about the long-term effects that playing American-style professional football has on the neurologic health of the players. For most of the previous history of football, the focus of media reports and scientific studies on footballrelated brain injuries was on the acute or short-term effects of serious, traumatic brain injuries such as intracerebral hematoma, subdural hematoma, and secondimpact syndrome [1]. Most of the preventative measures were related to improving the protection provided by the football helmet [2]. Studies of chronic or long-term neurologic effects of multiple concussions or subconcussive

*Correspondence: elehman@cdc.gov

Centers for Disease Control and Prevention, National Institute for Occupational Safety and Health, 4676 Columbia Parkway, R-13, Cincinnati, OH 45226, USA blows to the head (or both) related to football play were not conducted since it was generally believed that 'football concussions' that did not result in unconsciousness resolved within a matter of hours or days with no long-term cumulative effects. Consideration of longer-term neurologic problems or neurodegeneration was driven not by scientific research but by the spotlight that the popular sports press shone on what was happening to the health of popular players. The research that followed in the 1990s and 2000s indicated that football players may be at increased risk of neurodegenerative disease, presumably because they receive multiple blows to the head while playing football. This article will review the history of head injuries in relation to football play, summarize recent research that has linked football head injuries to neurodegeneration, and 
provide a discussion of the next steps for refining the examination of neurodegeneration in football players.

\section{Serious head injuries and fatalities}

American-style football has been played in the US since Walter Camp wrote the first set of football rules in 1876. Colleges picked up the game around the same time and formal league play commenced soon thereafter. The start of professional football dates to the late 1890s, and the first entirely professional team was constituted in 1897 [3]. Early football games, whether collegiate or professional, were violent affairs in which concussions were a common event. One newspaper account of the ArmyNavy game of 1890 reported that in one grand collision of the sides .... four of them cannot arise... the fourth is unconscious and even the surgeon cannot revive him' [4]. In response to the common occurrence of head injuries, rudimentary leather helmets were first worn in a game in 1893 but would not be mandatory in the National Football League (NFL) until 1940 [2]. Regardless of the availability of helmets, the level of violence and the number of serious head injuries increased until several prominent colleges and several states threatened to ban football unless major changes were made in how football was played. President Theodore Roosevelt intervened in 1905 to save the game from decline and by the following year substantial rule changes were made to reduce all injuries - in particular, injuries to the head and neck $[5,6]$. Even after the rule changes, death and injury from football play did not significantly decline. In 1931, the New York Times reported 275 deaths directly related to playing football between 1906 and 1931, and many of the deaths resulted from skull fractures and head injuries [7]. Further rule changes eliminating the 'flying block and tackle' were made in 1932 in an attempt to further reduce such injuries [8].

Throughout the first part of the 20th century, those involved in the medical treatment and management of football injuries continued to focus on minimizing serious head trauma since football fatalities continued to garner national press coverage. This is exemplified by a report that itemized 208 football fatalities between 1947 and 1959 with an escalating mortality rate from head and neck injuries supporting that focus [9]. However, a highly publicized injury to a well-known player in 1960 identified concussions as a serious medical problem that also required attention in professional football. Frank Gifford, a running back with the New York Giants, sustained a tackle to the head which resulted in a serious concussion that ended his season and contributed to his decision to retire for the 1961 season [10]. The transition to concussion monitoring is exemplified by a 1969 football injury report that was sponsored by the NFL and that tracked all injuries (including concussions) incurred by
New York Jets players between 1960 and 1968. Although the majority of the report discussed the rising incidence of knee injuries and the need to reduce severe head injuries, the fact that concussions were listed at all was a major advancement in the awareness of the seriousness of concussions in relation to the long-term neurologic health of players. Still, it is clear that identification of concussions was in its infancy given that only nine concussions were reported over the entire nine seasons. Less severe injuries, including subconcussive blows to the head, were felt to be important as they relate to making the player susceptible to other injuries resulting from a lack of alertness. Elsewhere, the report stated that a series of subconcussive blows do not produce an observable cumulative effect' [11].

\section{Post-concussion syndrome and the 'accumulative thing'}

The term 'post-concussion syndrome' was first used in an article published in 1934. The authors identified the syndrome by commonly reported symptoms of severe headache, irritability, memory problems, and dizziness, with symptoms persisting for months or years after the immediate consequences of head injury abated [12]. Not only did the 1934 article fully cover the clinical aspects and diagnosis of post-concussion syndrome it also suggested that multiple mild concussions, not just one severe concussion that results in unconsciousness, could lead to these lingering symptoms. This concept of accumulating neurologic damage was strengthened and further refined in articles published in 1962 [13] and 1975 [14]. The author of the 1962 article, for example, hypothesized that the effects of even slight concussions may never be totally reversible and that repeated occurrences could lead to permanent sequelae.

In spite of this growing body of literature, the NFL did not acknowledge that multiple concussions may be related to lingering or long-term neurologic sequelae in professional football until a number of high-profile players retired from the game because they had received multiple concussions. Roger Staubach decided to retire in 1980 after suffering through five concussions received during the 1979-80 season. Although Staubach said he was not concerned about the concussions, he remarked that one doctor was concerned that the concussions might be an 'accumulative thing' [15]. The accumulative issue took on greater importance in the late 1980s and early 1990s as a growing list of prominent players (Al Toon, Merrill Hoge, Troy Aikman, and Steve Young) retired from the game because of 'post-concussion syndrome' $[16,17]$. A number of scientific articles that directly connected post-concussion syndrome and mild concussion sequelae to playing football were subsequently published $[1,18,19]$. These authors were more strongly 
asserting that repeated mild traumatic brain injuries/ concussions were related to long-term, adverse neurologic outcomes experienced by athletes in general and professional football players in particular. The assumption that the 'dinged' states of athletic concussions were medically inconsequential could no longer be supported. In the face of this growing body of scientific evidence and the public awareness of concussion-related retirements of high-profile players, the NFL created the Committee on Mild Traumatic Brain Injury (MTBI). The creation of this committee directly and indirectly spurred a significant amount of research into the health effects of MTBI in general and of MTBI in the NFL in particular [20].

\section{Chronic traumatic encephalopathy and neurodegeneration in professional football}

The existence of lingering symptoms from concussions has been an identified medical condition for more than 200 years. In 1928, Martland identified an increased risk of neurodegenerative disorders among boxers. Affected boxers developed characteristics of Parkinson's disease and dementia-like symptoms that he termed the 'punch drunk syndrome'. Martland proposed that damage from the multiple head blows that boxers receive was the most plausible explanation for the post-concussion neuroses and psychoses that he termed 'post-traumatic encephalitis' [21]. A later author refined Martland's punch-drunk syndrome diagnosis to include cases involving senile dementia and Alzheimer psychosis. He went on to identify this condition by a 'less offensive' term: 'chronic traumatic encephalopathy' (CTE). The author asserted that CTE was a progressive and non-reversible condition that progressed steadily even after the exposure to head trauma had ceased [22]. Articles published in 1963 [23] and 1966 [24] reaffirmed the connection of CTE, exemplified variously by parkinsonian or dementia-like symptoms or both, to repeated blows to the head.

It is noteworthy that the concussion/MTBI connection to neurodegenerative disorders identified in boxers for many years was not considered to be relevant to football players until the 1980s. One of the first indications of chronic neurologic disorders in football players was reported in a 1987 Time magazine article about an apparent cluster of amyotrophic lateral sclerosis (ALS) occurring within the San Francisco 49ers football team. This very rare disease was diagnosed in three of the 55 football players who were on the 1964 San Francisco team roster. The article mentioned several possible causative factors, including exposure to metals, steroid use, exposure to pesticides, and a history of traumatic injuries, but made no mention of a connection with prior head injuries or concussions [25]. A 1994 mortality study of NFL players identified an increase in 'nervous system' deaths. This category of deaths included four cases of
ALS. The authors of the study identified this finding as important for future examination but did not highlight it in the report since the results did not reach statistical significance [26].

By the late 1990s, scientific opinion started to migrate from the concerns about football-related concussions causing post-concussion syndrome to something that could have chronic effects throughout a player's life. Researchers were now proposing that the effects of repeated concussions or MTBI (also referred to as cumulative traumatic brain injury, or CTBI) may be cumulative and result in an encephalopathy similar to that experienced by boxers and athletes in certain other contact sports. In discussing the CTBI sustained by football players during their playing careers, authors equated the neurologic conditions of players to those conditions described in the boxing literature: pugilistica dementia, CTE, or the punch-drunk syndrome $[27,28]$. Rabadi and Jordan [29] recognized that the majority of case reports recognizing CTBI (or CTE) in football had been reported in the lay press. Case reports of CTBI (CTE) were just starting to appear in the scientific literature. A case report of CTBI in a linebacker who retired after playing for 13 years in the NFL was published in 1998. This player, who received multiple concussions during his playing career, exhibited persistent difficulties with memory and concentration after retirement [18].

A major shift occurred in 2005 when Omalu and colleagues [30-33] began publishing a series of autopsy case studies of professional football players (and eventually other athletes) which identified CTE as a primary cause of death. The football players were generally longcareer players who were likely exposed to multiple $\mathrm{MTBI} /$ concussions throughout their careers. Omalu and colleagues defined CTE as 'a progressive neurodegenerative syndrome caused by a single, episodic, or repetitive blunt force impacts to the head and transfer of acceleration-deceleration forces to the brain... presents clinically after a prolonged latent period as a composite syndrome of mood disorders and neuropsychiatric and cognitive impairment' [33]. They found that CTE was primarily characterized pathologically by neurofibrillary tangles and neuritic threads in the cerebral cortex, subcortical nuclei/basal ganglia, hippocampus, and brainstem nuclei. In addition, all seven of the CTE-positive professional athletes for whom the authors were able to obtain apolipoprotein E (ApoE) genotyping exhibited at least one $\mathrm{e} 3$ allele, a risk factor for a specific type of dementia [30-33].

Additional comprehensive autopsy-based studies conducted by McKee and colleagues [34,35] supplemented and refined findings of Omalu and colleagues and, in addition to finding Alzheimer's disease and Parkinson's disease symptoms in CTE cases, found evidence of ALS 
in CTE cases. McKee and colleagues noted the similarities in the neuropathology of CTE to that of Parkinson's disease, Alzheimer's disease, and ALS but affirmed that CTE was a distinct neurodegenerative disease. CTE was a progressive tauopathy whose onset and severity were determined by the severity and number of traumatic brain injuries. Five of the 10 cases of CTE identified carried at least one ApoE e4 allele, a rate much higher than the $15 \%$ found in the general population. This study suggests that the ApoE e4 allele might be a risk factor for the development of CTE. In the three CTE cases that also developed ALS, the authors found a widespread proteinopathy (with TDP-43 protein) that extended into the spinal cord. Of the 51 confirmed CTE cases examined, five were professional football players; two of the three ALS cases were football players.

\section{How big is the risk for pro football players?}

Although there is an expanding body of recent research that is strengthening a connection between head injuries incurred during football play and occurrence of neurodegenerative diseases and CTE in players, the magnitude of that risk has been more difficult to ascertain. Virtually all of the research has focused on case reports of autopsies and self-identification by those who suspect incipient neurodegenerative effects. Stern and colleagues [36] (2011) accurately observed in a review article that there have been no randomized, case control studies of CTE and that there has been a selection bias in case reporting. To date, only three studies of professional players have not relied on autopsy or case reports and have presented reasonably unbiased measurements of neurodegenerative risk.

The first study $[37,38]$, which was based on a survey of 2,552 retired players, identified a threefold increased risk of depression and significant memory problems and a fivefold increased risk for mild cognitive impairment among players who reported incurring three or more concussions during their careers. Study authors noted that traumatic brain injury has been identified as a potential risk factor for neurodegenerative dementing disorders such as mild cognitive impairment, Alzheimer's disease, and Parkinson's disease. The average age of this cohort was 53.8 years, and the mean career duration of cohort members was 6.6 years.

A second study was based on a survey administered to a stratified sample of 1,063 retirement-vested NFL players [39]. Players 50 years old or older reported a diagnosis of 'dementia, Alzheimer's or other memory-related disease' at a rate five times higher than that of the general US male population, whereas players younger than 50 reported a rate 19 times higher. The average career length for this cohort was 7.3 seasons, and $58 \%$ of the surveyed players were between the ages of 45 and 69 .
A third study produced the first set of results that quantified the risk of neurodegenerative mortality among professional football players [40]. This cohort included 3,439 NFL players identified by a pension fund database of vested players with at least five credited playing seasons between 1959 and 1988. The median age of this cohort was 57 years, and the average career duration was eight years.

Although the overall mortality of this cohort was significantly lower than expected, standardized mortality ratio (SMR) - the ratio of observed deaths in the NFL cohort to the expected deaths in the general US population - was 0.53 , the neurodegenerative mortality was three times higher than that of the general US population, and those of two of the major neurodegenerative subcategories (Alzheimer's disease and ALS) were four times higher. Mortality from CTE could not be examined since it is not listed as a cause of death in any revision of the International Classification of Diseases. Since recent reports have found that football players who play certain positions may be at higher risk of concussion and thus may be at higher risk of neurodegenerative disease, the study authors stratified players into two categories based on position played to test that hypothesis: 'speed' players (quarterback, running back, halfback, fullback, wide receiver, tight end, defensive back, safety, and linebacker) and 'non-speed' players (all defensive and offensive linemen). Speed players are those who commonly build up considerable momentum prior to tackling or being tackled, whereas non-speed players usually engage other players soon after the football is snapped, thus mitigating the potential to build up momentum prior to contact $[41,42]$. The results of the speed/non-speed analysis showed significantly higher mortality for the speed category players in comparison with the US general population for neurodegenerative causes combined (SMR = 4.74), for Alzheimer's disease (SMR = 6.02), and for ALS (SMR = 6.24). Results from an internal analysis comparing speed with non-speed players showed that speed players had a threefold higher risk of dying from a neurodegenerative disease than non-speed players, providing some support for the hypothesis that players exposed to the higher-magnitude head impacts experienced increased neurodegenerative mortality. The authors cautioned that, owing to small numbers, these results were not statistically significant.

It is important to note that most of the autopsy studies and both of these latter studies examined players who played longer than the average career length for players. CTE (perhaps more in incipient form) has recently been identified in younger pro and collegiate football players as well as in ice hockey players, professional wrestlers, and military veterans [43]. Because no studies have looked systematically at neurodegeneration or CTE in 
shorter-term players, it has not been determined whether neurodegeneration or CTE is associated with many years of football play and, presumably, cumulative blows to the head.

\section{Limitations of current research and future directions}

In the last few years, significant progress has been made in detecting and defining the pathology of neurodegenerative disorders, including CTE, but comparatively less progress has been made in other factors related to the progression of those diseases in football players $[44,45]$. Whereas the incidence and prevalence of the major neurodegenerative diseases of Alzheimer's disease, Parkinson's disease, and ALS in the general population are known, the incidence and prevalence of CTE in the general population and among football players are still unknown. The 'exposure' element, presumably impacts to the head, is still poorly characterized: is it the number of impacts, the severity of the impacts, the location of the impacts, or some formula that accounts for all of these factors? Age at the time of injury plus genetic predisposition factors may also enter into the complicated equation. In summary, the following are areas that will require further exploration:

\section{Helmet effectiveness}

Beginning in 1973 when the first safety standards for football helmets were adopted, significant changes and improvements in helmet design have led to a virtual elimination of skull fractures and a marked reduction in intracranial hemorrhage [46]. The effect of the newer helmets on concussion incidence, however, is still unclear. One research effort estimated that the newer helmet technology has led to a $10 \%$ to $20 \%$ reduction in concussions in professional football [47]. Conversely, there is speculation that the modern helmet may have paradoxically increased the risk of concussion because of the large size and weight of the helmet and the perception among some players that it is safe to lead or make contact with their heads while blocking or tackling [48]. The results of ongoing research into helmet evaluation $[49,50]$ will be important in clarifying whether modern helmets have improved all aspects of brain health for football players and in identifying which technologies are most effective in protecting the head and brain.

\section{Quantification of exposure}

Studies referenced in this article were not consistent in how brain injuries were defined: some considered only traumatic brain injuries that resulted in unconsciousness or treatment in a medical facility, some considered only head injuries that were clinically diagnosed as concussions, some considered self-reported head injuries that would have been considered concussions if treated by a clinician, whereas others considered all concussive and subconcussive head injuries reported from multiple sources $[41,51,52]$. The studies and case reports that have relied on survey data or self-reports are susceptible to over-reporting bias. As a result, the ability to measure exposure effects across studies is severely limited. So that the effectiveness of future studies can be maximized, a consensus on the use of clinically practical measurements of blows to the head in football is direly needed.

To adequately study the hypothesis that the apparent excess risk of neurodegeneration among football players is caused by some accumulation of head injuries, it will be of paramount importance to be able to measure the intensity and frequency of brain injuries incurred over a number of years. A few studies have attempted to measure these injuries for a limited number of players over a limited period of time but such measurements have proven to be difficult and time-consuming [51-54]. The field of objective, biomechanical measurement of head impact is showing great promise, although the practicality of implementing the methods throughout all levels of football is still to be determined [53,54].

The limited amount of information available for younger or less experienced football players does not provide a clear picture of the risk they face. Recent autopsy studies have reported pathological findings of CTE in early-career professional football players and even among college and high school players $[33,55]$. The only study that has examined a historical cohort of high school players found no statistically significant increased risk of neurodegeneration in the players as compared with a matched cohort of non-players [56]. With recent autopsy studies reporting pathological findings of CTE in college-age and very young professional football players with short playing careers, it will be imperative to conduct studies that examine duration of play as a study variable. Additional studies to quantify the cumulative effects of brain injuries - and, in particular, the relative effects of concussive-level injuries - will be of particular importance in understanding the underlying disease mechanisms.

\section{Genetic susceptibility}

For more than 20 years, studies have linked the ApoE e4 allele to an increased risk of late-onset Alzheimer's disease. ApoE protein production significantly increases in response to injury and appears to play a role in the repair of the brain and nervous system [57]. Exactly how the ApoE e4 variant contributes to Alzheimer's disease is not clear, although one recent study indicates that it damages the blood-brain barrier and allows a dangerous build-up of beta-amyloid in the brain which could lead to neurodegeneration [58]. 
Studies of sports cohorts have examined the hypothesis that head injury may work synergistically with genetic susceptibility factors in the development of neurodegenerative disorders. Results have been mixed. One study of 30 boxers found that those with 12 or more professional bouts and ApoE e4 had significantly higher chronic traumatic brain injury scores than either boxers with fewer bouts or boxers without ApoE e4 [59]. A study of 53 active professional football players found that older players scored significantly lower in cognitive testing than younger players or players without ApoE e4 [60]. Conversely, a population-based cohort of 230 patients with Alzheimer's disease and 309 controls found no significant association between ApoE e4 and head injury [61]. A recent study of professional football players, including 68 players with CTE, reported no significant difference in ApoE e4 prevalence among the players with CTE as compared with the general US population [62].

Although there is increasing evidence that ApoE e4 variants are associated with increased risk of Alzheimer's disease and CTE in football cohorts, a more rigorous set of unbiased studies is still needed to clarify this relationship. Ideally such studies would accommodate analysis by career duration, position played, and concussion history. Such studies not only would assist in identifying those at risk for developing a neurodegenerative disease but also may help in providing targeted therapeutic treatments among susceptible individuals [58].

\section{Earlier detection and prevention}

Unfortunately, there are no cures for neurodegenerative diseases, and current treatments are variously effective in slowing the progression of some specific neurodegenerative diseases or in moderating disease symptoms [63]. In the case of CTE, positive identification of the disease can only be made post-mortem.

Preliminary work has begun to try to identify signs of neurodegeneration among living football players. One study used multiple brain imaging methods and neuropsychological testing to identify clinically significant brain abnormalities in living active and retired professional football players [64]. A second study has used positron emission tomography to detect brain tau deposits in living players with mood and cognitive disorders. Though preliminary, this method shows promise in identifying neurodegenerative diseases in the early stages of development [65].

Prior to the lengthy process of developing clinical approaches to disease detection and prevention, practical methods should be considered to minimize the injuries that may be triggering neurodegeneration in football players. In recent years, changes in NFL rules have been implemented with the intention of reducing the incidence of concussion and subconcussive head injuries among players. Such changes have included moving forward the kickoff line, eliminating the blocking wedge during kickoff returns, penalizing blocks and tackles involving the head or neck, and mandating certain medical protocols for players who exhibit concussion-like symptoms. In a talk before the Harvard School of Public Health, NFL commissioner Roger Goodell identified additional shortand long-term steps that need to be taken to reduce concussions and possible longer-term sequelae: research on concussion and related genetic factors, improved equipment and helmet design, strict enforcement of playing rules with an emphasis on those that involve hits to the head, and improved technology to measure the impact of blows to the head [66].

\section{Conclusions}

There is considerable evidence that multiple and recurring concussive and subconcussive blows to the head can be deleterious to the brain and may result in neurodegeneration. However, a number of questions on how and why neurodegeneration may occur in football players still need to be answered: Is it based on the accumulation of multiple brain insults or caused by a cascade of events triggered by several severe brain injuries? Are there synergistic effects between genetic susceptibilities and brain injury? Why are neurologic impairments appearing in collegiate and early-career pros when it has been assumed that such effects were relegated to long-term pro players? Are there other environmental factors involved in neurodegeneration?

Confirming that repetitive head injuries, even if subconcussive in nature, cause neuronal death that leads to CTE or other serious neurodegeneration will require additional studies using multiple study design methods. Additional studies that attempt to quantify the cumulative effects of head injuries - and, in particular, the relative effects of concussive- and subconcussive-level injuries - will be of particular importance in understanding the underlying disease mechanisms. Fully effective disease-prevention interventions will not be possible until more is known about the exposure-disease relationship.

This article is part of a series on Traumatic Brain Injury, edited by

Robert Stern. Other articles in this series can be found at

http://alzres.com/series/traumaticbraininjury

\section{Abbreviations}

ALS, amyotrophic lateral sclerosis; ApoE, apolipoprotein E; CTBI, chronic traumatic brain injury; CTE, chronic traumatic encephalopathy; MTBI, mild traumatic brain injury; NFL, National Football League; SMR, standardized mortality ratio.

Competing interests

The author declares that he has no competing interests. 


\section{Acknowledgments}

This study was funded by the intramural research program of the National Institute for Occupational Safety and Health (NIOSH). The sponsor reviewed and approved the final submission but did not have a role in design and conduct of the study; in the collection, analysis, and interpretation of the data; or in the preparation of the manuscript. The author wishes to thank Sherry Baron, Misty Hein, and Christine Gersic of NIOSH for their previous work on the cohort study of NFL players. The author wishes to thank Douglas Trout of $\mathrm{NIOSH}$ for his review and valuable comments on the manuscript. The findings and conclusions in this report are those of the author and do not necessarily represent the views of the $\mathrm{NIOSH}$.

\section{Published: 22 July 2013}

\section{References}

1. Bailes JE, Cantu RC: Head injury in athletes. Neurosurgery 2001, 48:26-46.

2. Levy ML, Ozgur BM, Berry C, Aryan HE, Apuzzo ML: Birth and evolution of the football helmet. Neurosurgery 2004, 55:656-662.

3. NFL Record \& Fact Book 2010 (Official National Football League Record and Fact Book). New York: Time Home Entertainment; 2010.

4. The Navy whips the Army. New York Times. November 30, 1890.

5. Abolish football, says Harvard Bulletin. New York Times. October 19, 1905.

6. Miller JJ: The Big Scrum: How Teddy Roosevelt Saved Football. New York: Harper Collins Publishers; 2011.

7. 40 players killed in football season. New York Times. December 6, 1931

8. Langford WS: Football changes protect players. New York Times. October 7, 1932.

9. Schneider RC, Reifel E, Crisler HO, Oosterbann BG: Serious and fatal football injuries involving the head and spinal cord. JAMA 1961, 177:106-111.

10. Anderson D: A 50-year-old hit that still echoes. New York Times. November 20, 2010.

11. Football Injuries: Papers Presented at a Workshop, Contract PH43-64-44, Task Order 3. Washington DC: National Academy of Sciences; 1970.

12. Strauss I, Savitsky N: Head injury: neurologic and psychiatric aspects. Arch Neurol Psychiatr 1934, 31:893-955.

13. Symonds C: Concussion and its sequelae. Lancet 1962, 279:1-5.

14. Gronwall D, Wrightson P: Cumulative effect of concussion. Lancet 1975, 306:995-997.

15. Roger Staubach calls it quits. The Charleston SC News and Courier. April 1, 1980.

16. Farber M: The worst case: doctors warn that repeated concussions can lead to permanent brain dysfunction. Sports Illustrated. December 19, 1994.

17. Plaschke B: NFL Report: Information that should make their heads spin. The Sporting News 1995, 219:32.

18. Kelly JP, Rosenberg JH: The development of guidelines for the management of concussion in sports. J Head Trauma Rehabil 1998, 13:53-65.

19. Erlanger DM, Kutner KC, Barth JT, Barnes R: Neuropsychology of sportsrelated head injury: dementia pugilistica to post concussion syndrome. Clin Neuropsychol 1999, 13:193-209.

20. Pellman EJ: Background on the National Football League's research on concussion in professional football. Neurosurgery 2003, 53:797-798.

21. Martland HS: Punch drunk. JAMA 1928, 91:1103-1107.

22. Critchley M: Medical aspects of boxing, particularly from a neurological standpoint. BrMed J 1957, 1:357-362.

23. Mawdsley C, Ferguson FR: Neurological disease in boxers. Lancet 1963 282:795-801.

24. Miller H: Mental sequelae of head injury. Proc R Soc Med 1966, 59:257-261.

25. Wallis C, Dorfman A: Medicine: probing a mysterious cluster. Time. February 23, 1987.

26. Centers for Disease Control and Prevention, National Institute for Occupational Safety and Health (NIOSH): National Football League Players Mortality Study. Cincinnati, OH: NIOSH; 1994. Health Hazard Evaluation 88-085.

27. Jordan BD, Tsairis P, Warren RF (Eds): Sports Neurology. Philadelphia: Lippincott-Raven Publishers; 1998.

28. Bailes JE, Lovell MR, Maroon JC (Eds): Sports-Related Concussion. St Louis: Quality Medical Publishing, Inc; 1999.

29. Rabadi $\mathrm{MH}$, Jordan BD: The cumulative effect of repetitive concussion in sports. Clin J Sport Med 2001, 11:194-198.

30. Omalu BI, DeKosky ST, Minster RL, Kamboh MI, Hamilton RL, Wecht CH:
Chronic traumatic encephalopathy in a National Football League player. Neurosurgery 2005, 57:128-134.

31. Omalu BI, DeKosky ST, Hamilton RL, Minster RL, Kamboh MI, Shakir AM, Wecht $\mathrm{CH}$ : Chronic traumatic encephalopathy in a National Football League player: Part II. Neurosurgery 2006, 59:1086-1093.

32. Omalu BI, Hamilton RL, Kamboh MI, DeKosky ST, Bailes J: Chronic traumatic encephalopathy (CTE) in a National Football League player: case report and emerging medicolegal practice questions. J Forensic Nurs 2010, 6:40-46

33. Omalu BI, Bailes J Hamilton RL, Kamboh MI, Hammers J, Case M, Fitzsimmons $\mathrm{R}$ : Emerging histomorphologic phenotypes of chronic traumatic encephalopathy in American athletes. Neurosurgery 2011, 69:173-183.

34. McKee AC, Cantu RC, Nowinski CJ, Hedley-Whyte ET, Gavett BE, Budson AE, Santini VE, Lee HS, Kubilus CA, Stern RA: Chronic traumatic encephalopathy in athletes: progressive tauopathy after repetitive head injury. J Neuropathol Exp Neurol 2009, 68:709-735.

35. McKee AC, Gavett BE, Stern RA, Nowinski CJ, Cantu RC, Kowall NW, Perl DP, Hedley-Whyte ET, Price B, Sullivan C, Morin P, Lee HS, Kubilus CA, Daneshvar DH, Wulff M, Budson AE: TDP-43 proteinopathy and motor neuron disease in chronic traumatic encephalopathy. J Neuropathol Exp Neurol 2010, 69:918-929.

36. Stern RA, Riley DO, Daneshvar DH, Nowinski CJ, Cantu RC, McKee AC: Longterm consequences of repetitive brain trauma: chronic traumatic encephalopathy. PM R 2011, 3:S460-S467.

37. Guskiewicz KM, Marshall SW, Bailes J, McCrea M, Harding HP Jr., Matthews A, Mihalik JR, Cantu RC: Recurrent concussion and risk of depression in retired professional football players. Med Sci Sports Exerc 2007, 39:903-909.

38. Guskiewicz KM, Marshall SW, Bailes J, McCrea M, Cantu RC, Randolph C, Jordan BD: Association between recurrent concussion and late-life cognitive impairment in retired professional football players. Neurosurgery 2005, 57:719-726.

39. Weir DR, Jackson JS, Sonnega A: National Football League Player Care Foundation: Study of Retired NFL Players. Ann Arbor, MI: University of Michigan, Institute for Social Research; September 10, 2009.

40. Lehman EJ, Hein MJ, Baron SL, Gersic CM: Neurodegenerative causes of death among retired National Football League players. Neurology 2012, 79:1970-1974.

41. Pellman EJ, Powell JW, Viano DC, Casson IR, Tucker AM, Feuer H, Lovell M, Waeckerle JF, Robertson DW: Concussion in professional football: epidemiological features of game injuries and review of the literature part 3. Neurosurgery 2004, 54:81-96.

42. Broglio SP, Surma T, Ashton-Miller JA: High school and collegiate footbal athlete concussions: a biomechanical review. Ann Biomed Eng 2012, 40:37-46.

43. Omalu B, Hammers JL, Bailes J, Hamilton RL, Kamboh MI, Webster G, Fitzsimmons RP: Chronic traumatic encephalopathy in an Iraqi war veteran with posttraumatic stress disorder who committed suicide. Neurosurg Focus 2011, 31:1-10.

44. Baugh CM, Stamm JM, Riley DO, Gavett BE, Shenton ME, Lin A, Nowinski CJ, Cantu RC, McKee AC, Stern RA: Chronic traumatic encephalopathy: neurodegeneration following repetitive concussive and subconcussive brain trauma. Brain Imag Behav 2012, 6:244-254.

45. Gavett BE, Stern RA, McKee AC: Chronic traumatic encephalopathy: a potential late effect of sport-related concussive and subconcussive head trauma. Clin Sports Med 2011, 30:179-188.

46. Levy ML, Ozgur BM, Berry C, Aryan HE, Apuzzo ML: Analysis and evolution of head injury in football. Neurosurgery 2004, 55:649-655.

47. Viano DC, Pellman EJ, Withnall C, Shewchenko N: Concussion in professional football: performance of newer helmets in reconstructed game impacts part 13. Neurosurgery 2006, 59:591-606

48. Repanich J: Helmets alone won't save football from concussions [http:// sportsillustrated.cnn.com/nfl/news/20121219/nfl-concussions-helmet/].

49. Collins M, Lovell MR, Iverson GL, Ide T, Maroon J: Examining concussion rates and return to play in high school football players wearing newer helmet technology: a three-year prospective cohort study. Neurosurgery 2006, 58:275-286.

50. Rowson S, Duma SM: Development of the STAR evaluation system for football helmets: integrating player head impact exposure and risk of concussion. Ann Biomed Eng 2011, 39:2130-2140.

51. Broglio SP, Sosnoff JJ, Shin S, He X, Alcaraz C, Zimmerman J: Head impacts during high school football: a biomechanical assessment. J Ath/ Train 2009, 
44:342-349

52. Crisco JJ, Fiore R, Beckwith JG, Chu JJ, Brolinson PG, Duma S, McAllister TW, Duhaime AC, Greenwald RM: Frequency and location of head impact exposures in individual collegiate football players. J Ath Train 2010, 45:549-559.

53. Mihalik JP, Bell DR, Marshall SW: Measurement of head impacts in collegiate football players: an investigation of positional and event-type differences. Neurosurgery 2007, 61:1229-1235

54. Funk JR, Rowson S, Daniel RW, Duma SM: Validation of concussion risk curves for collegiate football players derived from HITS data. Ann Biomed Eng 2012, 40:79-89.

55. Schwarz A: Former Bengal Henry found to have had brain damage. New York Times. June 28, 2010.

56. Savica R, Parisi JE, Wold, LE, Josephs KA, Ahlskog JE: High school football and risk of degeneration: a community-based study. Mayo Clin Proc 2012, 87:335-340.

57. Strittmatter WJ, Saunders AM, Schmechel D, Pericak-Vance M, Enghild J, Salvesen GS, Roses AD: Apolipoprotein E: high-avidity binding to $\beta$ amyloid and increased frequency of type 4 allele in late-onset familial Alzheimer disease. Proc Natl Acad SciU S A 1993, 90:1977-1981.

58. Bell RD, Winkler EA, Singh I, Sagare AP, Deane R, Wu Z, Holtzman DM, Betsholtz C, Armulik A, Sallstrom J, Berk BC, Zlokovic BV: Apolipoprotein E controls cerebrovascular integrity via cyclophilin A. Nature 2012, 485:512-516.

59. Jordan BD, Relkin NR, Ravdin LD, Jacobs AR, Bennett A, Gandy S: Apolipoprotein $\mathrm{E} \varepsilon 4$ associated with chronic traumatic brain injury in boxing. JAMA 1997, 278:136-140.

60. Kutner KC, Erlanger DM, Tsai J, Jordan B, Relkin NR: Lower cognitive performance of older football players possessing apolipoprotein $E \varepsilon 4$. Neurosurgery 2000, 47:651-658.
61. O'Meara ES, Kukull WA, Sheppard L, Bowen JD, McCormick WC, Teri L, Pfanschmidt M, Thompson JD, Schellenberg GD, Larson EB: Head injury and risk of Alzheimer's disease by apolipoprotein E genotype. Am J Epidemiol 1997, 146:373-384.

62. McKee AC, Stein TD, Nowinski CJ, Stern RA, Daneshvar DH, Alvarez VE, Lee HS, Hall G, Wojtowicz SM, Baugh CM, Riley DO, Kubilus CA, Cormier KA, Jacobs MA, Martin BR, Abraham CR, Ikezu T, Reichard RR, Wolozin BL, Budson AE, Goldstein LE, Kowall NW, Cantu RC: The spectrum of disease in chronic traumatic encephalopathy. Brain 2013, 136:43-64

63. Lunn JS, Sakowski SA, Hur J, Feldman EL: Stem cell technology for neurodegenerative diseases. Ann Neurol 2011, 70:353-361.

64. Amen DG, Newberg A, Thatcher R, Jin Y, Wu J, Keator D, Willeumier K: Impact of playing American professional football on long-term brain function. J Neuropsychiatry Clin Neurosci 2011, 23:98-106.

65. Small GW, Kepe V, Siddarth P, Ercoli LM, Merrill DA, Donoghue N, Bookheimer SY, Martinez J, Omalu B, Bailes J, Barrio JR: PET scanning of brain tau in retired National Football League players: preliminary findings. Am $J$ Geriatr Psychiatry 2013, 21:138-144

66. Roger Goodell's presentation at the Harvard School of Public Health [http://profootballtalk.nbcsports.com/2012/11/16/ full-text-of-roger-goodells-presentation-at-the-harvard-school-of-public-health/].

doi:10.1186/alzrt188

Cite this article as: Lehman EJ: Epidemiology of neurodegeneration in American-style professional football players. Alzheimer's Research \& Therapy 2013,5:34. 